\title{
How the Internet Influences the Development of Modern Market Economy
}

\author{
Jingxuan Fang1, Dong $\mathrm{Xu}^{2}$ \\ ${ }^{1}$ Department of Digital Media Studies, University of Rochester, Rochester, USA \\ ${ }^{2}$ Department of Electrical Engineering and Computer Science, University of Missouri, Columbia, MO, USA \\ Email: jfang8@u.rochester.edu,xudong@missouri.edu
}

How to cite this paper: Fang, J. X., \& Xu, D. (2020). How the Internet Influences the Development of Modern Market Economy. American Journal of Industrial and Business Management, 10, 1002-1012. https://doi.org/10.4236/ajibm.2020.105067

Received: May 3, 2020

Accepted: May 23, 2020

Published: May 26, 2020

Copyright (c) 2020 by author(s) and Scientific Research Publishing Inc. This work is licensed under the Creative Commons Attribution International License (CC BY 4.0).

http://creativecommons.org/licenses/by/4.0/

\begin{abstract}
The internet has a tremendous influence on our life in modern society. It not only penetrates many aspects of people's daily routines but also brings great changes to the world. This paper utilizes China's economy as an example to analyze how the internet impacts economic development. The relativity between the internet and economy is analyzed through professional models. With the digital revolution of the internet, the development of the market economy will be tightly connected with the internet in the current time and future.
\end{abstract}

\section{Keywords}

Internet, Economy Development, GDP, Relativity

\section{Introduction}

As the first internet structure appeared roughly 50 years ago, it continuously brings us huge changes. Many reformations have been done based on the internet (Cunningham, 2002). For example, in China, with the improvement of the basic infrastructure, the internet has penetrated all levels across society. According to Fastdata Report, the sales volume base of China 5G mobile phones has already occupied $37.3 \%$ in total shipment numbers in 2020 Q1 (Fastdata Report of 2020 China Internet Development Trend).

In 2010, China has surpassed Japan to become the second-largest world economy entity based on the data of gross domestic product (GDP) (IMF, 2011). It was a milestone for the market economy around the world. From then on, the internet continues to play an important role in China's economic development with high-speed growth in the long term. A brief but precise analysis could be done here highlighting the growth of GDP corresponding to the positive internet 
influence on the business and industrial expansion, etc.

\section{Internet Development Trend}

In the past 10 to 20 years, the internet has been an evolving media which brought rapid growth to the marketing field directly. Almost everyone who has PC could set up personal or company websites and promote their brands. And the relevant investment is almost zero. The rule of the game has been completely changed (Xiong et al., 2016). In the current society, mobile phones are widely used, and this further pushes the boom of mobile internet.

Internet is becoming a marketing and commercial tool in this digital age. It has brought us an unimaginably huge reformation. The reason behind this is that coverage of the internet could almost reach everyone and everywhere, so our life and future will be affected correspondingly. Not only to each individual but also our organizations, work environments, families, and businesses, etc, the internet leads us to try more and experience more. In the evolution of human history, when there's efficient and close communication, there's evolutionary progress that would lead to a new stage of marketing and business. The internet age has surpassed any other times in history. There is nothing like the depth and width that the internet covers, and it makes us dizzy. In a word, the internet is instant and global (Heslop \& Angell, 1994).

\subsection{Global Internet Development Situation}

Today, the internet has become a global trend, which the accumulated global internet users have already reached 4.5 billion at the end of 2019. In the meantime, such an ongoing growth of this trend is displayed in Figure 1 (199IT, 2020) (Chinabaogao, 2020) (MNW, 2019).

Based on the announced data from ITU, QuestMobile, China State Industry \& Information Ministry, and AUS, the detailed statistics of global mobile users and global internet users is shown in Figure 2 (QuestMobile, 2017) (Economy Daily, 2018) (Chyxx, 2019). It could be easily found that there's a growing statistic trend for the number of internet users. In the meantime, the number of non-internet users is dropping.

It is shown that the internet is gradually being widely used in a worldwide range in Figure 1. In 2010, the worldwide internet penetration rate is around $29 \%$. In 2019, the number grows to $58 \%$. With the great expansion of both internet access and its user base, it is easy to expand a variety of businesses and strengthen the potential customer base in the market economy.

It can be found in Figure 2 that global mobile users almost balance with the number of the world population. Two billion of them use the mobile internet. From then on, the number of global mobile users has surpassed the world population every year. This is a great platform for the development of the market economy. With the increasing number of mobile internet users, the efficiency of the market economy is further improved greatly since these users could be reached out from anywhere easily. 


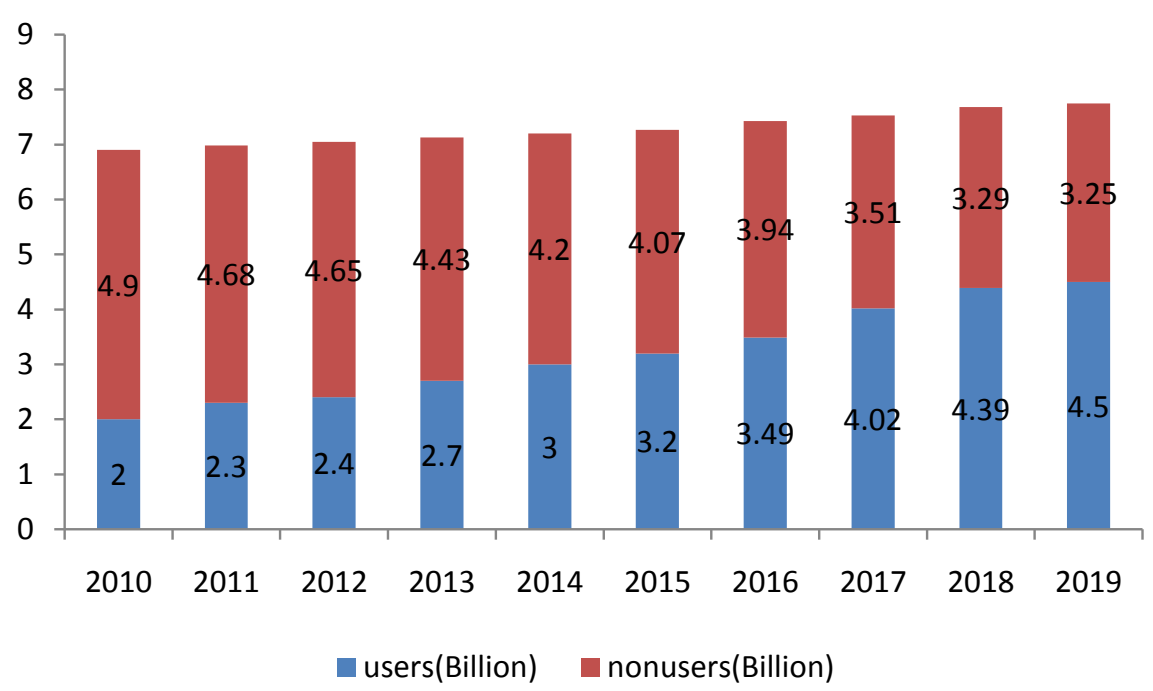

Figure 1. Global internet user situation.

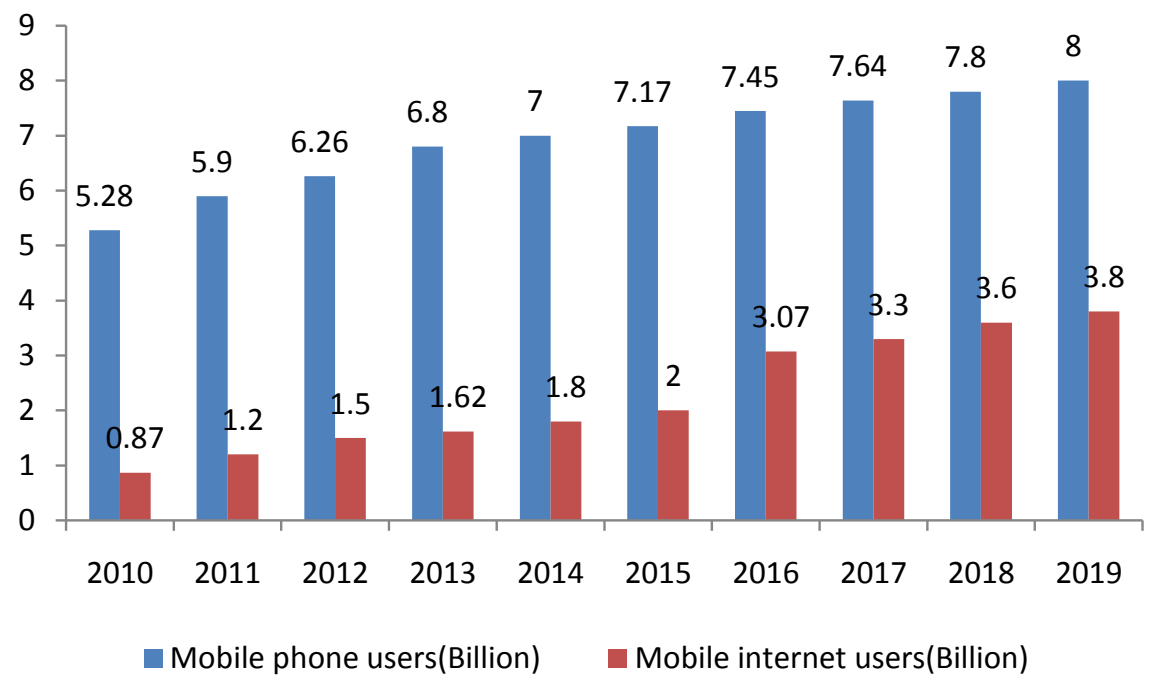

Figure 2. Global mobile user situation.

Comparing to the traditional business model, the internet now becomes a simple and user-friendly platform for business and marketing promotion. Product introduction and promotion could be shown perfectly through the world wide web, computers, or mobile screens. Customers don't need to physically attend the events at the exchanging site since they can now depend on the computer or mobile network which providing the flexible exchange at home, office, and anywhere else.

\subsection{Internet Development Situation in China}

At the end of 2019, the number of global internet users hit a line of 4.5 billion. And this data is particularly stunning in China when it reaches 854 million as Figure 3 shown (ITU, 2014) (Na, 2011) (Yang \& Cheng, 2014) (CNNIC, 2015) (China Internet Development Report 2019). 


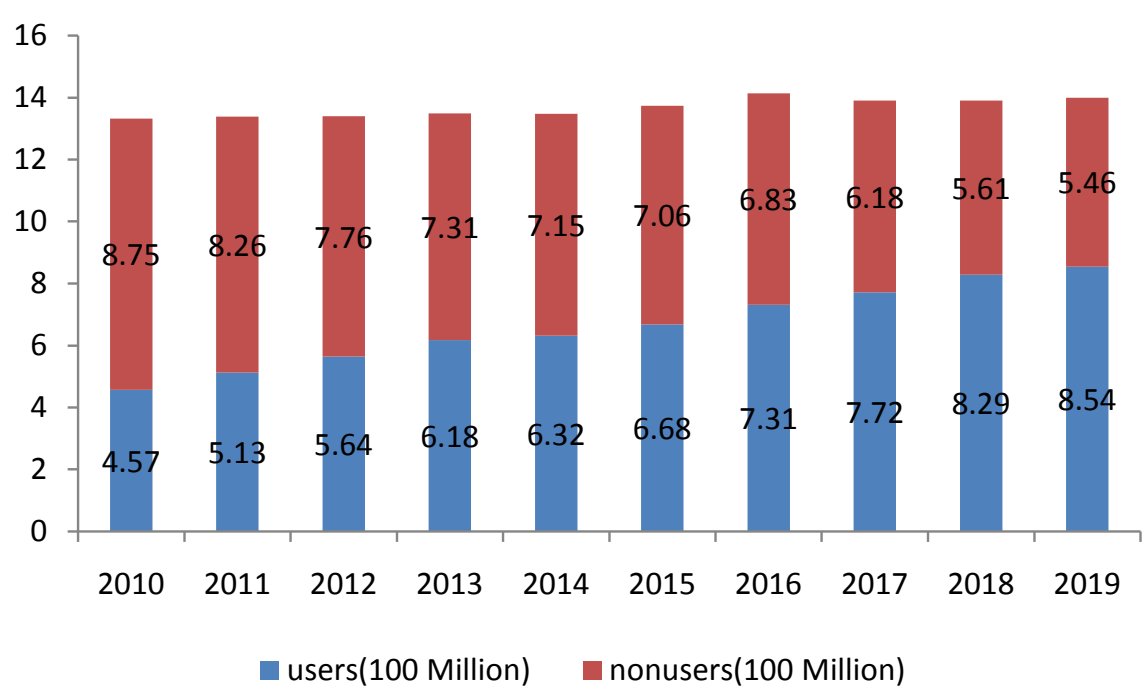

Figure 3. China internet user situation.

It is presented that the internet is widely used in China. In 2010, China's internet penetration rate is about $34.3 \%$. In 2019, the number grows to $61 \%$.

According to the data from China Internet Association Data and China State Statistics Bureau, China's mobile user situation is cited in Figure 4 (CIA, 2016) (CCTV, 2020).

In 2019, Chinese mobile users have reached 1.6 billion based on the number of mobile card purchases. 1.3 billion customers use mobile internet. This builds up a broad platform for both marketing improvement and business growth since these users are linked within the network.

\section{Internet Brings Big Changes}

With the appearance of the internet, big changes have been brought to people in many aspects of our life. Here is an analysis with details.

\subsection{The Influence of the Internet on Consumption}

In 2019, the global total GDP is roughly 8663 billion USD. Currently, the sum market value of the global top 20 internet companies is about 633 billion USD as shown in Figure 5. Among these 20 companies, the USA and China occupies 12 (shown in blue in Figure 5) and 6 respectively. Internet business plays a very important role in both the first economic entity and the second economic entity.

Among the global top 20 internet companies, the six Chinese companies are Alibaba, Tencent, Meituan, JD, Netease \& Baidu which are shown in red in Figure 5. Their businesses will be analyzed briefly. Their commerce mainly focuses on food, clothing, shelter, and transportation-necessities of life. Alibaba's Taobao \& TMALL establish digital platforms for users to do business to fulfill the basic needs of everybody. Tencent highlights not only the entertainment of people but also the investment in many domains to satisfy people's daily needs like Didi taxi, etc. Meituan's primary business is food takeout. Then it enlarges 


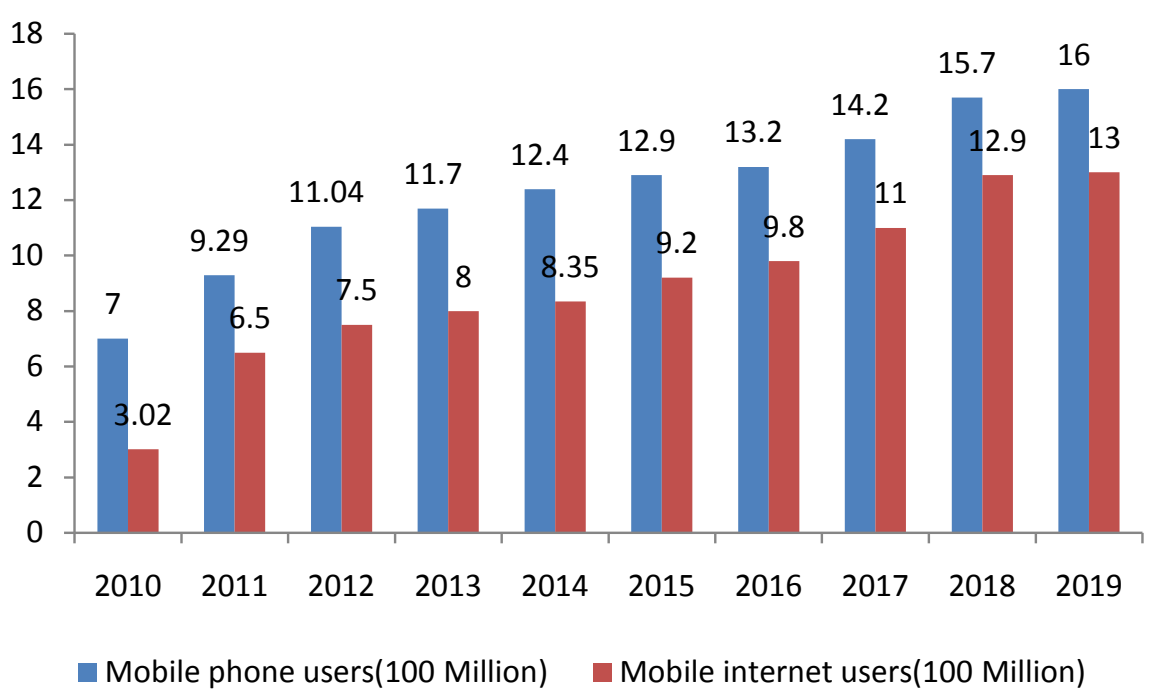

Figure 4. China mobile user situation.

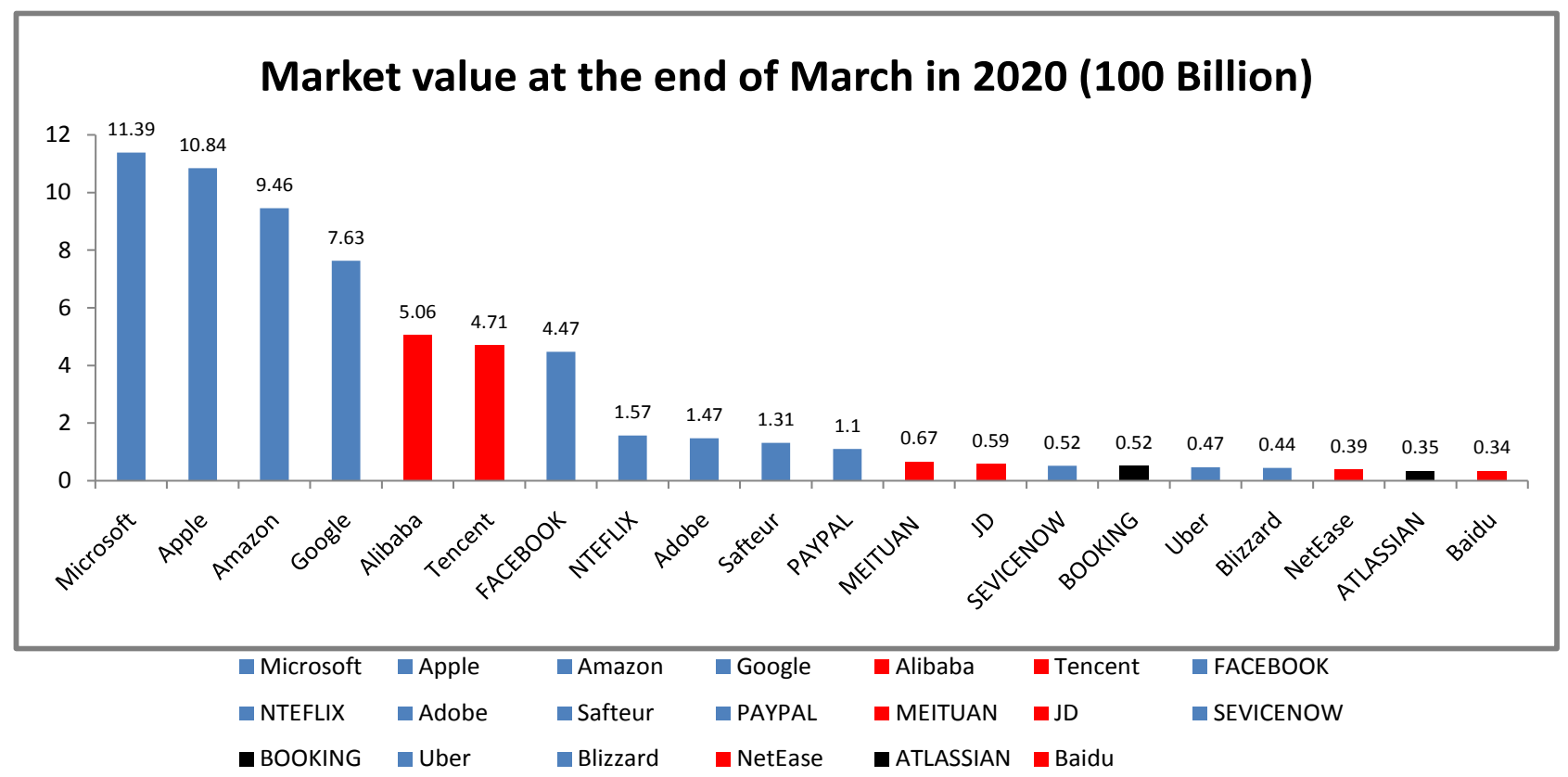

Figure 5. The market value of global top 20 internet companies.

to other businesses of basic life related to tourism, etc. JD's advantage is about logistics, which makes good use of its logistics to develop a connected platform for various vendors and brands. Netease shares similar characteristics as Tencent, but its internet technique is more advanced. Baidu favors advertisements and searching engine systems, just like Google. Besides the businesses related to necessities, Alibaba and JD also invest a lot of time and funding in the medical care domain, represented by remote diagnosis and curing advisory, etc.

At the end of March in 2020, the market value of total Chinese internet companies ranking top 50 globally is around 1314 billion USD. The number is roughly about $10 \%$ GDP of China in 2019. This powerfully demonstrates that 
the internet can bring big changes and values to our life at present.

\subsection{The Influence of the Internet on Culture and Entertainment}

The internet will produce advantages and supply tools to rapidly develop several industries in the cultural and entertainment fields. The example from China will be studied below.

In the past few years, the Chinese cultural industry developed very quickly. With the boom of China's economy, the quality and quantity of population growth, the consumption driven by the new middle class, digitization related to the increasing population, and the cultural industry of China is forecasted to surpass the USA in 2030 (Sohu, 2018).

With the appearance of internet drama in China, the cultural industry accelerates its development. Two years ago, civil internet drama Day \& Night overseas issuance right was bought by Netflix. Day \& Night would perform in over 190 countries. Many foreigners waited for renewing on Wuxiaworld and Gravity Tales. Rules of Survival of Netease and Word Connect also marched to the leaderboard of the App Store of the USA. All these examples could verify the cultural industry of China is becoming stronger in a short period.

Price Waterhouse predicted that China's GDP would reach 2650 billion USD and surpass the USA in 2030. The economy would set up talent, capital, technique, equipment, and market foundation and create the precondition for the improvement of the cultural industry. With the fast expansion of the internet in China, especially mobile internet, film, teleplay, video game, streaming services, and music demonstrate an explosive growth. Now, China has the second-largest film market in the world. Many researchers predicted that China might be the top one shortly. Almost all Chinese top internet companies have already stepped into the cultural industry.

\subsection{Internet with the Payment System and Its Finance}

Third-party mobile payment is the most important and fundamental service of the internet. In 2019, the number of third-party mobile payment users reaches 950 million in China. WeChat and Alipay rank the top one and two. Though third-party mobile payment hits 25 hundred billion RMB in 2019 and gets YOY growth $20.1 \%$, it only occupies $39.1 \%$ market shares. The other $60.9 \%$ belong to banking institutions.

Internet financing is a new model based on payment, cloud calculation, social internet \& search engine, APPs, and other internet tools. It is a kind of inclusive financial system. Comparing to traditional financing, it has alike characteristics: strong transparency, high participation, good cooperation, low cost, easy operation, etc. Unlike a traditional business model that displays $80 \%$ performance coming from $20 \%$ products, the long tail model is explained instead. Only if both storage and channel are sufficient and smooth enough, the pile-up of small commercial niches and non-mainstream markets could compete with the pri- 
mary market. The long tail model needs two preconditions. One is the cost should be low enough. The other is there should be enough customers. Then, the profit could be made correspondingly.

\section{The Impact of E-Commerce Based on the Internet to a Market Economy and GDP}

Because of the internet being applied in a variety of ways, it's unsurprising that buyers or sellers could save a considerable amount of cost in physical store management, employee payment, office rent, raw materials, and supplies, etc. This definitely could lead to an increase in margin and an improvement in efficiency.

According to the announced data from eMarketer and 2019 Global E-Commerce Market Trend Report, the worldwide growth trend of E-commerce revenue and the share growth rate are displayed in Figure 6 and Figure 7 (eMarketer, 2014) (iiMedia, 2019).

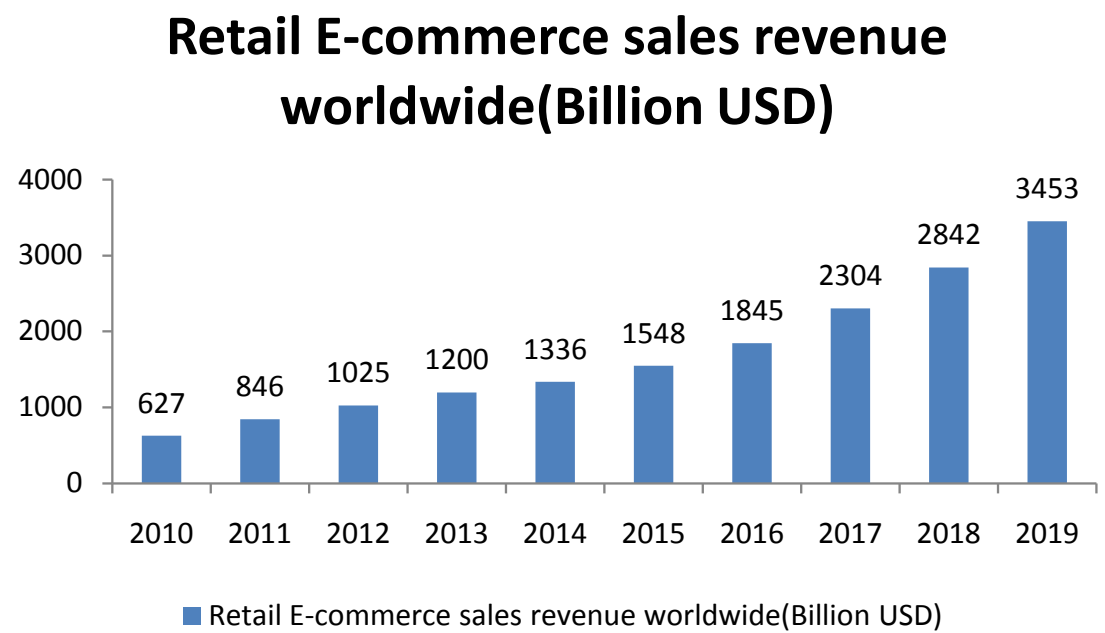

Figure 6. Worldwide E-commerce revenue.

\section{E-commerce share of total retail sales revenue worldwide}

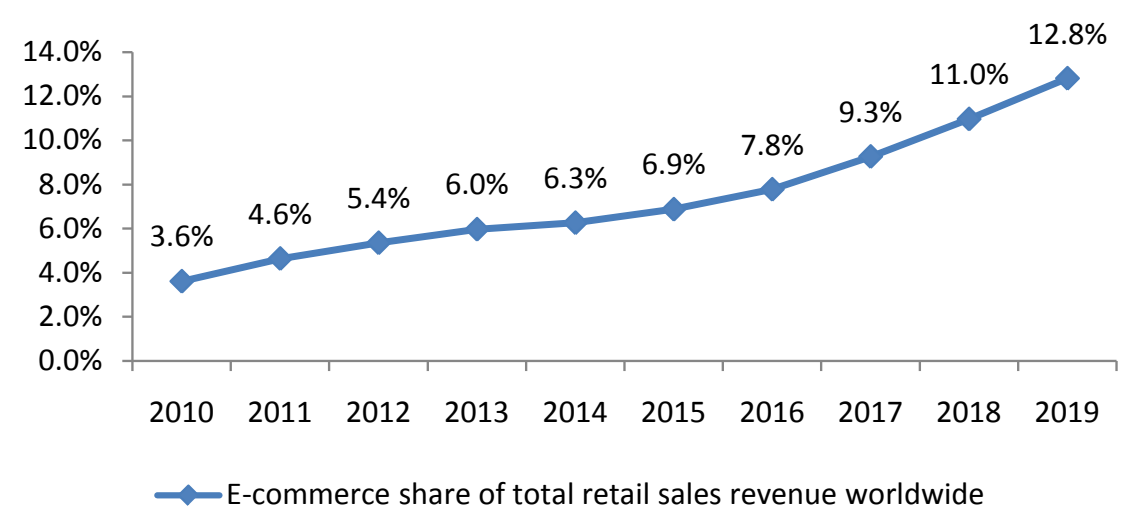

Figure 7. Worldwide E-commerce revenue share. 
It is found that Global E-commerce sales revenue grows quite fast in the past ten years from Figure 6. Furthermore, the E-commerce business share is increased compared to the global retail sales revenue. The function of the internet is obvious, which affects a lot in various segments of commodity circulation. Whatever advertisement, product exhibition through VR or AR, or order placing, payment, channel development, logistics auditing, or other aspects, the internet's contribution to efficiency and effectiveness of businesses could be easily found.

In China, a similar thing is happening. However, the changing speed is much higher. Chinese E-commerce revenue growth trend and share growth rate are depicted in Figure 8 and Figure 9 (Chyxx, 2020).

\section{China E-commerce share of total retail sales revenue}

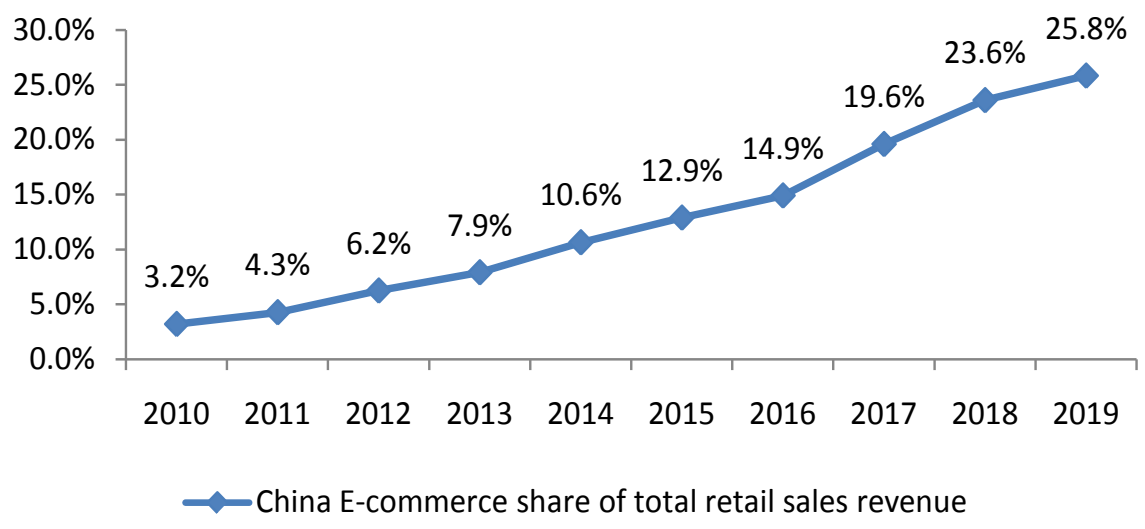

Figure 8. China E-commerce revenue.

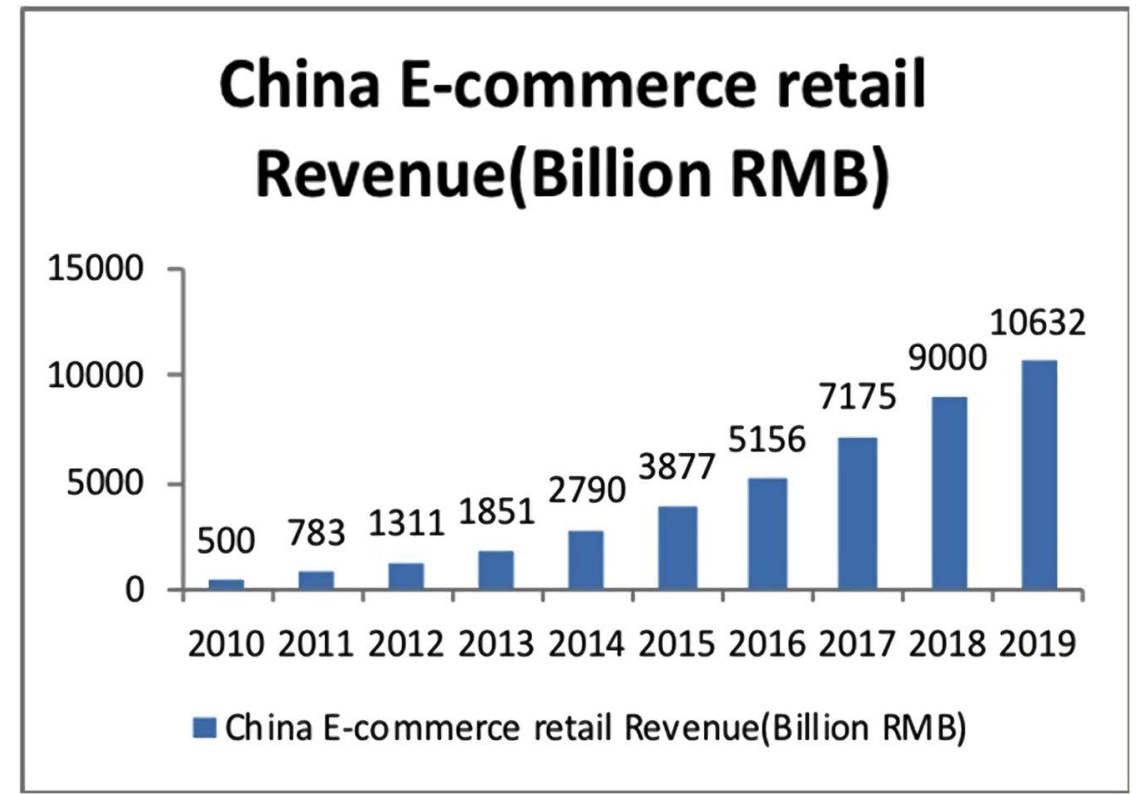

Figure 9. China E-commerce revenue share. 
From Figure 8 and Figure 9, it is clear that the Chinese internet business growth rate is much higher than in other countries. The internet will become a useful engine to enhance the market economy and GDP especially with the existence of 5G. With the tremendous growth of E-commerce, its contribution to GDP is much higher.

Through the development of the internet, the internet of things (IoT), mobile internet, big data, and cloud calculation technology, E-commerce grows rapidly. According to the United Nations Conference on Trade and Development (UNCTAD) forecast, the business focuses on E-commerce occupies about $30 \%$ to $40 \%$ of the entire global trade revenue. Soon, the number will continue to grow without a definite endpoint.

In 2020, the coronavirus global epidemic painfully strikes our society, leaving people with limited time to get fully prepared to face the losses in businesses. Under this global environment, the internet displays its advantages in many aspects such as remote education based on online class, remote healthcare, online conference and financing, business contract signing through the cloud, online streaming services, etc.

\section{Relationship between China's GDP and Internet Usage}

According to the data from China State Statistics Bureau and ICT, the relationship between China's GDP and the number of internet users is demonstrated in Figure 10.

With the number of internet users increasing every year in China, China's GDP is also growing. From the statistics in Karl Pearson's theory-correlation analysis, the relativity between China's GDP and the number of internet users in China can be analyzed with the below formula (Mao et al., 2017).

$$
r=\left[\sum\left(x_{i}-X\right)\left(y_{i}-Y\right)\right] / \sqrt{\left[\sum\left(x_{i}-X\right)^{2} \sum\left(y_{i}-Y\right)^{2}\right]}
$$

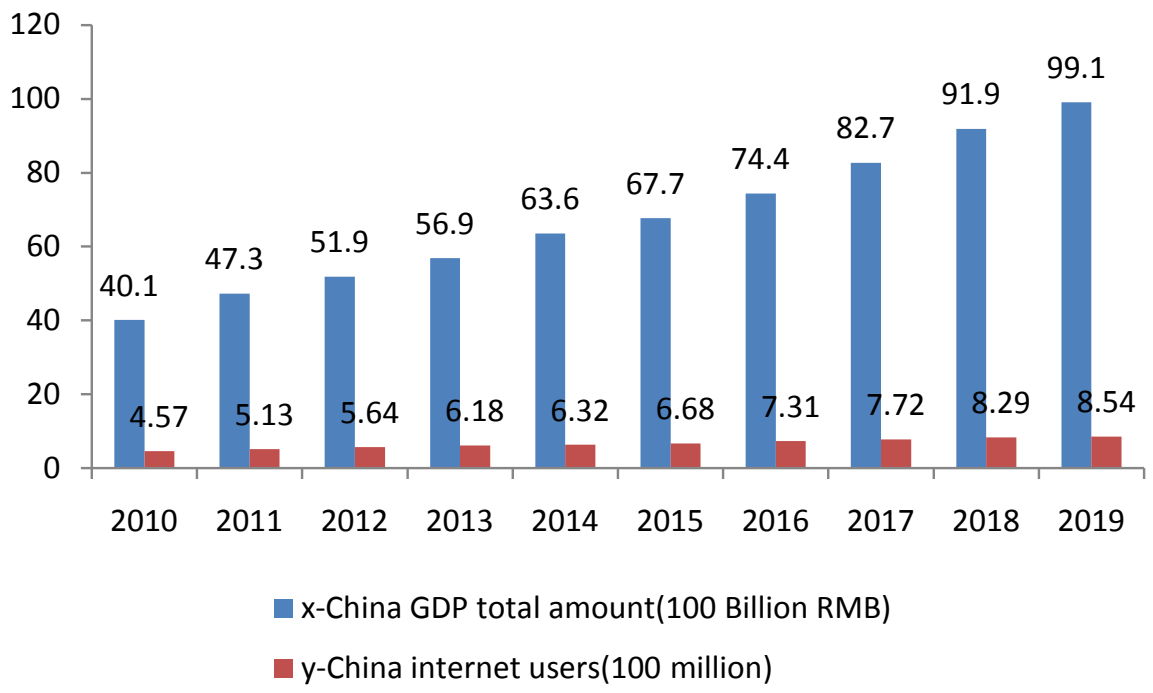

Figure 10. China's GDP and internet users in China. 
$r$ is the correlation coefficient to describe the potential relationship. $r>0$ means positive relativity; $r<0$ means negative relativity; $r=0$ means 0 relativity. $x_{i}$ means the total amount of China's GDP and $i=1,2, \ldots 10 ; y_{i}$ is the number of internet users and $i=1,2, \ldots 10 ; X$ is average China's GDP from 2010 to 2019, while $Y$ is the average of internet users in China from 2010 to 2019.

Based on formula (1), $r=15.18 / 99.62=0.15>0$. So, China's GDP has positive relativity with the number of internet users in China, which means internet usage is one of the most important factors leading to the growth of the China economy.

A further situation can be analyzed here. As the internet is being used more widely, more internet users appear. When the internet is utilized for business purposes, more market revenue could be generated correspondingly. Because of the effectiveness and efficiency of the internet, more GDP could then be expected. As a result, the positive relativity between GDP and the number of internet users is reasonable. However, the growth rate of internet users might be relatively slow due to the spreading penetration. And this could negatively impact the GDP growth and cause the bottleneck situation sometime in the future.

\section{Summary}

The internet has a tight relationship with the market economy, and GDP is one of the strongest indicators here. The research and analysis in the paper are taken only the total amount of GDP instead of per capita growth because based on the announced data from China State Statistics Bureau, China's GDP per capita has also grown from 4360 USD in 2010 to 10276 USD in 2019. As a result, the findings of the impact of the internet on per capita growth will ideally be the same. Because of the content limit, this topic might be analyzed with more details in future articles. China's high-speed per capita growth in the past 20 years is undoubtfully a miracle.

In conclusion, the internet brings great progress to the world. And the most valuable point of the internet is not only that it creates a lot of new things and brings inspiration in different fields, but the key point is people could share more information in almost all current industries through this network. Based on the exchange of information and virtual data integration, the relevant resources could be utilized to the maximum extent. To sum up, the internet plays a significant role in the development of a successful market economy.

\section{Conflicts of Interest}

The authors declare no conflicts of interest regarding the publication of this paper.

\section{References}

199IT (2020). We Are Social: 2020 Global Internet Brief Report. http://www.199it.com/archives/1020700.html 
2019 Global E-Commerce Market Trend Report.

https://www.cifnews.com/article/40276

CCTV (2020).

http://news.cctv.com/2020/01/17/ARTIcfUKrgvarC84iryqConh200117.shtml

China Internet Association (CIA) (2016). Report on 2015 China Internet Industry Summary and 2016 Development Trend.

China Internet Development Report 2019. http://www.bjnews.com.cn/feature/2019/10/20/639061.html

China Internet Network Information Center (CNNIC) (2015). Statistical Report on Internet Development in China.

Chinabaogao (2020). http://market.chinabaogao.com/it/021TOS52020.html

Chyxx (2019). http://www.chyxx.com/industry/201911/809141.html

Chyxx (2020). http://www.chyxx.com/industry/202001/830998.html

Cunningham, M. J. (2002). E-Business. London: Capstone Publishing.

Economy Daily (2018).

https://baijiahao.baidu.com/s?id=1604434921682736156\&wfr $=$ spider\&for $=\mathrm{pc}$

eMarketer (2014). 2014 Global e-Commerce Report.

Fastdata Report of 2020 China Internet Development Trend.

Heslop, B., \& Angell, D. F. (1994). The Instant Internet Guide-Hands-On Global Networking.

iiMedia (2019). https://www.iimedia.cn/c1020/67328.html

IMF (International Monetary Fund) (2011). World GDP Report of 2010.

ITU (2014). World Telecommunication/ICT Indicators Database.

Mao, X. Z., Zhang, L. J., Mao, T. X., Wang, Y. Z., \& Huang, J. (2017). The Research of Fund Influence Based on Correlation Analysis of Karl Pearson and Regression Analysis. Journal of Zhejiang Sci-Tech University (Social Science), 38, 306-311.

MNW (2019). http://www.mnw.cn/news/world/2233248.html

Na, L. (2011). The Link CEIBS, Volume 2. Shanghai: CEIBS.

QuestMobile (2017). Global Mobile Internet User Report. https://m.sohu.com/a/138041838_126808

Sohu (2018). https://www.sohu.com/a/216207585_697770

Xiong, W., Zhao, Z., \& Fang, J. X. (2016). Influence of Internet plus to International Business Development. American Journal of Industrial and Business Management, 6, 541-549.

Yang, T., \& Cheng, L. (2014). Chinese Payment and Settlement Industry Operation Report. Beijing: China Social Sciences Press. 